\title{
Persistent non-solar forcing of Holocene storm dynamics in coastal sedimentary archives
}

\author{
Philippe Sorrel ${ }^{1,2 \star}$, Maxime Debret ${ }^{2 \star}$, Isabelle Billeaud ${ }^{2,3}$, Samuel L. Jaccard ${ }^{4}$, Jerry F. McManus ${ }^{5}$ \\ and Bernadette Tessier²
}

Considerable climatic variability on decadal to millennial timescales has been documented for the past 11,500 years of interglacial climate ${ }^{1-3}$. This variability has been particularly pronounced at a frequency of about 1,500 years, with repeated cold intervals in the North Atlantic ${ }^{1,3}$. However, there is growing evidence that these oscillations originate from a cluster of different spectral signatures ${ }^{4}$, ranging from a 2,500-year cycle throughout the period to a 1,000-year cycle during the earliest millennia. Here we present a reappraisal of high-energy estuarine and coastal sedimentary records from the southern coast of the English Channel, and report evidence for five distinct periods during the Holocene when storminess was enhanced during the past 6,500 years. We find that high storm activity occurred periodically with a frequency of about 1,500 years, closely related to cold and windy periods diagnosed earlier $^{1-3}$. We show that millennial-scale storm extremes in northern Europe are phase-locked with the period of internal ocean variability in the North Atlantic of about 1,500 years 4 . However, no consistent correlation emerges between spectral maxima in records of storminess and solar irradiation. We conclude that solar activity changes are unlikely to be a primary forcing mechanism of millennial-scale variability in storminess.

Recent studies ${ }^{4}$ demonstrate that several Holocene palaeoclimatic records include a continuous 2,500-year cycle over the Holocene and a 1,000-year cycle during the early Holocene, whereas the mid- to late Holocene is marked by the gradual appearance of a cyclic period of 1,500 years not present in solar proxies. This period has been attributed to ocean dynamics associated with a stabilization of the signal after $6,000 \mathrm{BP}$ as sea-level rise slowed and meltwater fluxes ceased ${ }^{4}$. Internal oceanic forcing is responsible for the dynamic behaviour of the North Atlantic in the transfer, amplification and/or modulation of climatic variations in the global thermohaline and atmospheric circulation mode. These climatic fluctuations are linked with important cultural and socio-economic reorganizations in Europe and, through teleconnections, globally. Instrumental, historical and proxy data have documented rapid and large-scale changes on the physiography of coastal areas in northern coastal Europe at decadal timescales ${ }^{5}$. A comprehensive understanding of millennial-scale North Atlantic climate modulation and its spectral signature on storm dynamics is, however, less obvious in part owing to the lack of high-resolution coastal archives. Here, we investigate North Atlantic ocean-atmosphere interactions during periods of increased storminess throughout the mid- to late Holocene, as recorded in high-energy estuarine and other coastal sedimentary archives. As yet, coastal sedimentary deposits have been primarily screened to decipher the impact of climatic changes on coastal evolution and dynamics ${ }^{6-12}$.

The macrotidal Seine Estuary and Mont-Saint-Michel Bay (MSMB) are two coastal sedimentary systems both located along the southern coast of the English Channel in northwestern France (Fig. 1). This area is well suited to investigate longterm storminess variability because it is exposed to the rapidly changing North Atlantic climate system, which has a substantial influence on the Northern Hemisphere in general. The MSMB and Seine Estuary have two of the thickest Holocene coastal sedimentary wedges in northwestern Europe, allowing for highly temporally resolved environmental reconstructions ${ }^{13,14}$ (Fig. 2 and Supplementary Table S1). At both sites, the main architectural change in the sedimentary infills occurred at about $6,500 \mathrm{cal}$ B $\mathrm{P}$ when the sea-level rise significantly decelerated concomitant with the disappearance of North American ice sheets.

In the Seine Estuary ${ }^{13}$, the late Holocene record of the outer estuary documents the occurrence of storm deposits disrupting the background sedimentary infill with an apparent periodicity of $\sim 1,500$ years (that is, at about 4,400-3,950, 3,300-2,700, $1,600-1,250$ and $600-300$ cal BP). A similar pattern of increased storminess was indicated in the infill of the MSMB in open tidal flat and back-barrier successions ${ }^{14}$ at about 5,800-5,500, 4,500-4,000, 3,300-2,700 and 1,200-1,000 cal BP. At both sites, intervals of increased storminess are coeval to the late Holocene North Atlantic drift-ice discharge events ${ }^{13,14}$.

These data, collected from high-energy estuaries, complement other independent records of storminess and flooding from northern European sheltered coastal environments between southeast England and Sweden (Fig. 1). The timing of storminess maxima in northwestern France closely matches that from coastal environments from England ${ }^{6,7}$, Scotland ${ }^{8}$, Ireland ${ }^{9}$, the Netherlands ${ }^{10}$, Denmark ${ }^{11}$ and Sweden ${ }^{12}$ at about 4,300, 2,800, 1,400 and $400 \mathrm{cal} \mathrm{BP}$, which have been interpreted as reinforced wind activity associated with a more frequent passage of cyclones. On the basis of nine independently dated records, we propose here a stacked chronology of palaeostorm activity in northern coastal Europe, and consequently define five Holocene storm periods (HSPs) consisting of the most widespread stormy intervals during the mid- to late Holocene (Fig. 1): HSP I $(5,800-5,500 \mathrm{cal} \mathrm{вP),}$ HSP II $(4,500-3,950 \mathrm{cal} \mathrm{вр})$, HSP III $(3,300-2,400$ cal вр), HSP IV (1,900-1,050 cal вр) and HSP V (600-250 cal вр), the last one

\footnotetext{
${ }^{1}$ Laboratoire de Géologie de Lyon (LGL-TPE) : Terre, Planètes, Environnements (UMR CNRS 5276), Université Claude Bernard-Lyon 1 , F-69622 Villeurbanne, France, ${ }^{2}$ Laboratoire Morphodynamique Continentale et Côtière (M2C) (UMR CNRS 6143), Université de Caen Basse-Normandie et Université de Rouen, F-14000 Caen / F-76821 Mont-Saint-Aignan, France, ${ }^{3}$ Total Exploration and Production, CSTJF, F-64018 Pau, France, ${ }^{4}$ Geological Institute, ETHZ Zürich CH-8092, Switzerland, ${ }^{5}$ Lamont-Doherty Earth Observatory, Department of Earth and Environmental Science, Columbia University, Palisades, New York 10964-8000, USA. *e-mail:philippe.sorrel@univ-lyon1.fr; maxime.debret@univ-rouen.fr.
} 

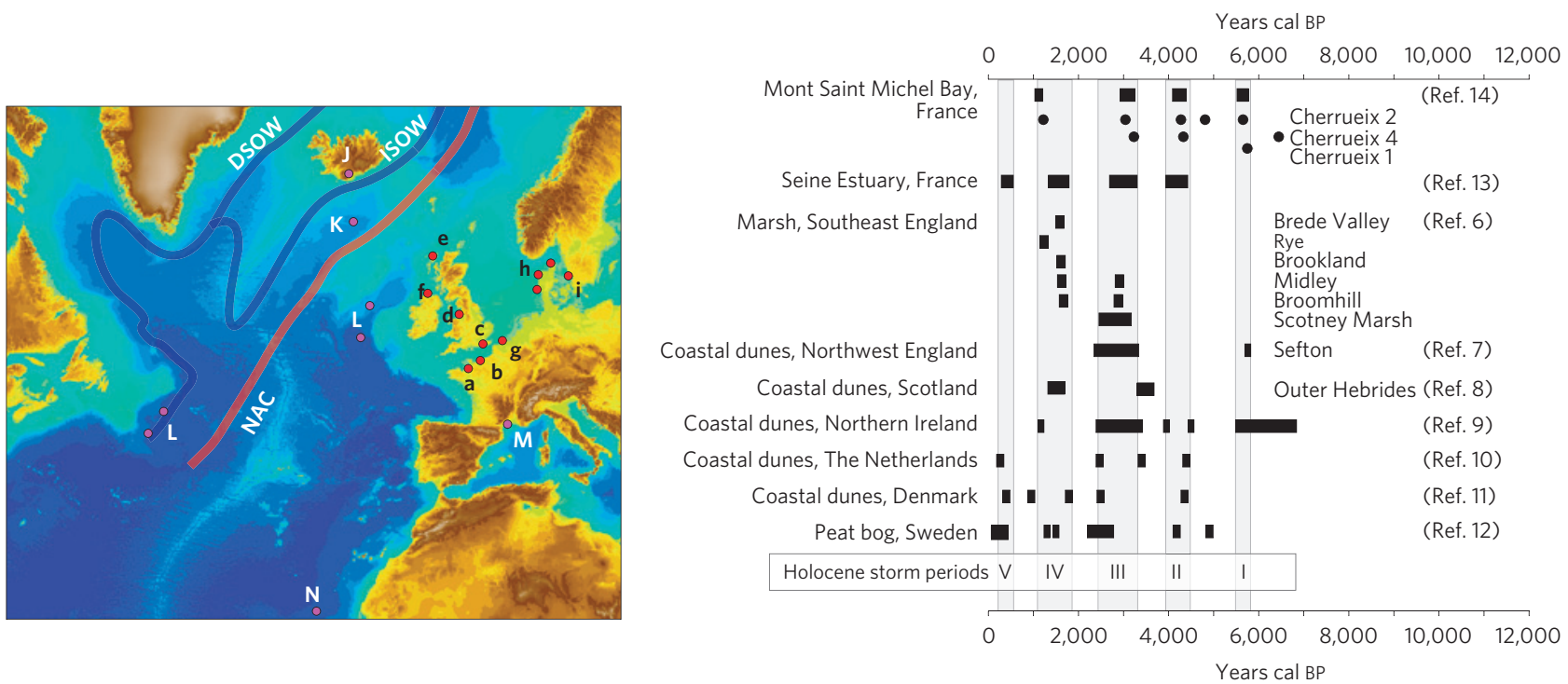

Figure 1 North Atlantic core sites and the HSPs in northern Europe. Left: Map of the North Atlantic region showing the coastal locations (red points) of (a,b) Seine Estuary and MSMB cores in northwestern France; (c-i) coastal records from northern coastal Europe: (c,d) England ${ }^{6,7}$; (e) Scotland ${ }^{8}$; (f) Ireland ${ }^{9}$; (g) the Netherlands ${ }^{10}$; (h) Denmark ${ }^{11}$; (i) Sweden ${ }^{12}$. Light pink dots refer to core sites from the North Atlantic (J, ref. 15; K, ref. 21; L, ref. 1), the Mediterranean Sea (M, ref. 25) and the eastern subtropical Atlantic (N, ref. 23). The water masses are the North Atlantic Current (NAC), the Iceland Scotland Overflow Water (ISOW) and the Denmark Strait Overflow Water (DSOW). Right: Storminess maxima recorded in coastal archives from locations a-i. The grey shadings defines the five HSPs identified during the late Holocene.

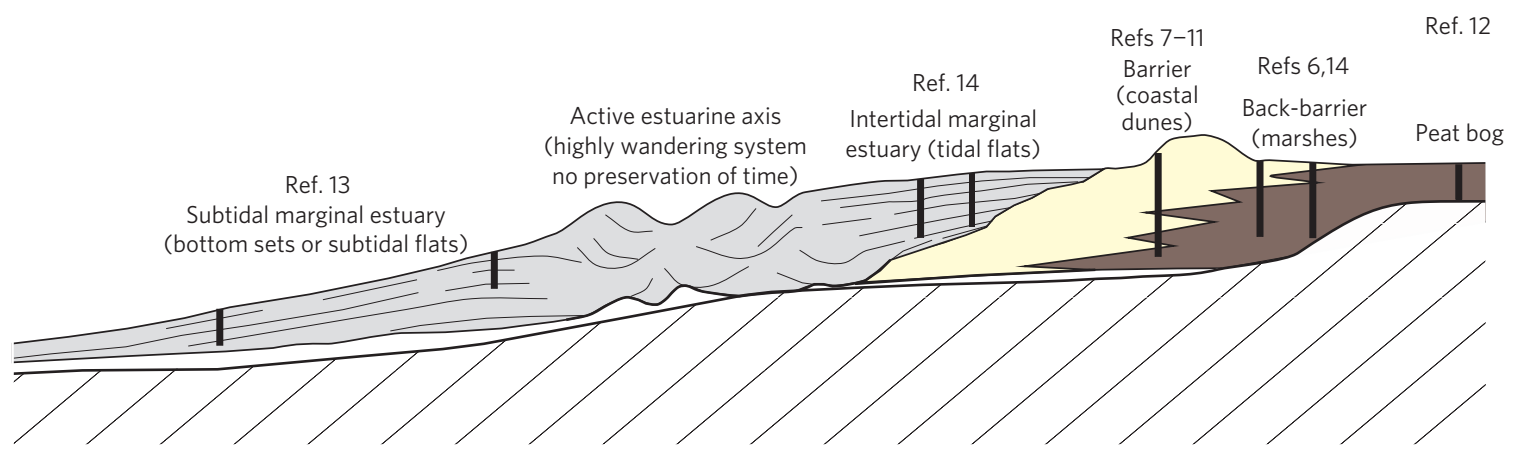

Figure 2 | Schematic cross-section of a sedimentary coastal wedge as preserved in the MSMB and Seine Estuary environments. Sedimentary coastal archives of Holocene climate changes were usually retrieved from backshore environments, such as aeolian dune fields, back-barrier lagoons or peat bogs ${ }^{6-12}$. In this study we present new sedimentary archives collected from open-marine settings in the macrotidal MSMB and Seine Estuary estuaries (red points a,b in Fig. 1). We use an exceptionally large data set consisting of very high-resolution seismic data (130 km and $600 \mathrm{~km}$ of seismic profiles acquired from the Seine Estuary and MSMB, respectively) complemented by well-dated storm deposits (thick, coarse sandy shell intervals) selected from 43 (Seine Estuary) and 50 (MSMB) vibrocores ${ }^{13,14}$.

coinciding with the early to mid-Little Ice Age (LIA). Composite evidence gathered from multiple geomorphologic environments reduces the potential influence of local environmental variability on the shared signal, and thereby reveals a more robust record of regional coastal responses to large-scale climate variability on millennial timescales. In this regard, our HSP record from northern coastal Europe illustrates storminess maxima that are strikingly similar to those reported in a terrestrial palaeoclimate record south of Iceland ${ }^{15}$ (Fig. 3b) and in sea-salt sodium proxies from Greenland ice cores ${ }^{16}$. This suggests that the concurrent long-term climate deteriorations in northern coastal Europe and over the North Atlantic respond coevally to a common mechanism. Shifts in atmospheric circulation in the North Atlantic region are closely linked to the surface hydrography of the ocean. In particular, the time series of the Icelandic storminess record exhibits peaks corresponding to the ice-rafted debris (IRD) maxima ${ }^{1}$, which have also been tied to cooling events in the North Atlantic ${ }^{3,17}$ and glacial advances in Scandinavia ${ }^{2}$.
Furthermore, several of these late Holocene cooling events coincided with times of reduction in the Atlantic meridional overturning circulation ${ }^{17}$.

The close correspondence among the HSPs, Icelandic dust records and the IRD data ${ }^{1}$ requires further consideration (Fig. 3). A reappraisal of the widespread 1,500-year variability of Holocene climate by using wavelet transform analyses suggested that the IRD time series ${ }^{1}$ is composed of two robust wavelengths forced by solar activity (1,000- and 2,500-year cycles) together with a 1,500 -year cycle $^{4}$. The 1,500-year cycle is assigned to an internal oceanic forcing that has become dominant in the past 5,000 years. Indeed, the mid-Holocene period was characterized by a substantial reorganization of the North Atlantic circulation pattern, in which the solar imprint in palaeoclimate records gradually became less apparent as the Atlantic overturning circulation became robustly established. Hence, atmospheric circulation changes seem to coincide with oceanic variability during the late Holocene. To unravel the relative importance 


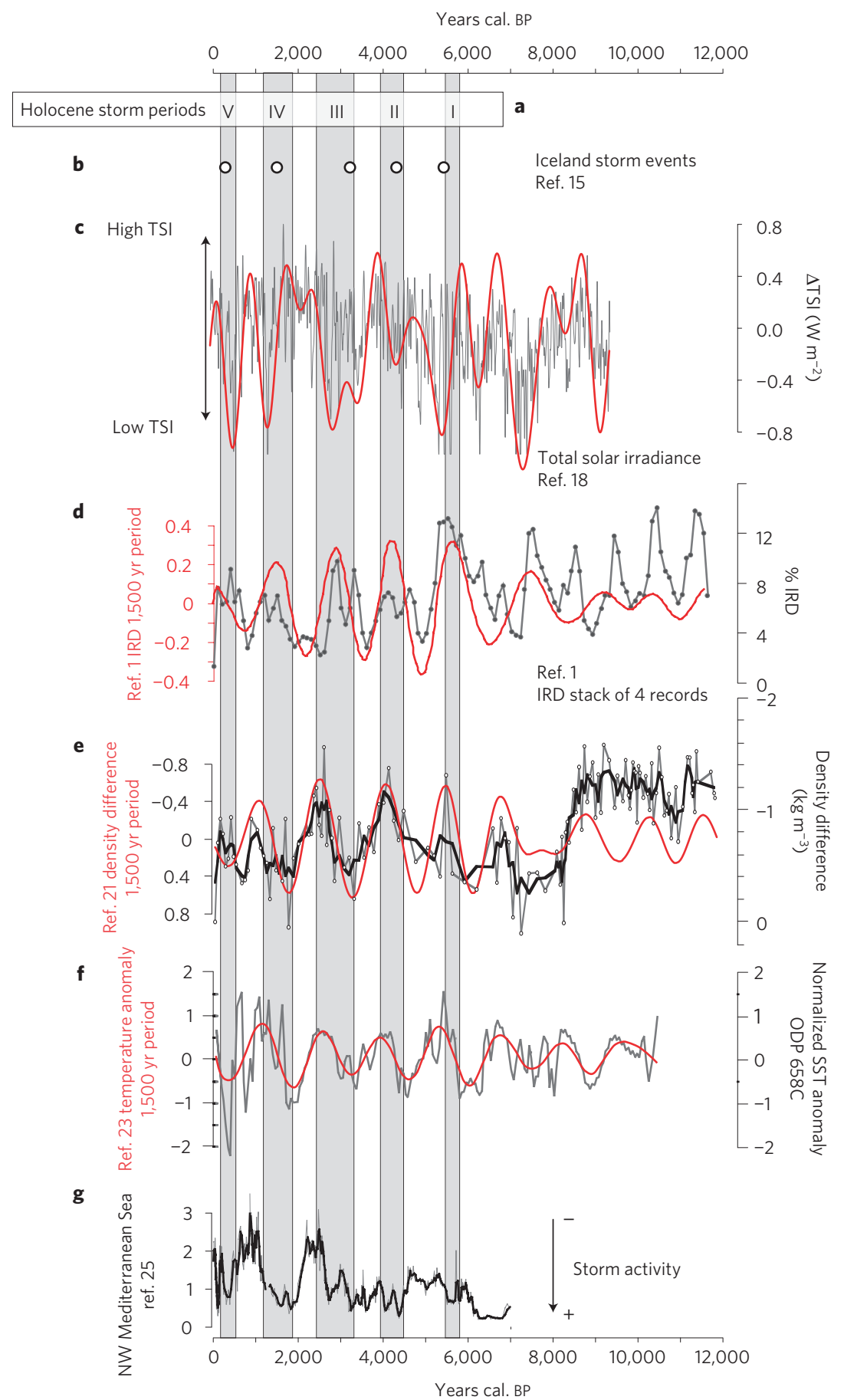

Figure 3 | North Atlantic climate records, the solar forcing and the HSPs during the late Holocene. a, HSPs (this study). b, Iceland storm events ${ }^{15}$. c, $\mathrm{TSI}^{18}$ (red curve; wavelet reconstruction for the wavelengths between 950 and 2,800 years). d, IRD stack series of four drillings

(MC52 - MD29191+ MC21-GGC22; ref. 1; grey) and the 1,500-year period (red). e, Water density difference (stratification increases upwards) between Globorotalia bulloides and G. inflata (grey) with three-point running means (black) and the 1,500-year period (red; ref. 21). f, Detrended temperature anomalies from core ODP 658 C (grey) and the 1,500-year period (red; ref. 23). g, Smectite/(illite+ chlorite) ratio in the northwest Mediterranean Sea ${ }^{25}$. Grey shading highlights the match between the HSPs and North Atlantic climate and TSI records across the key intervals.

of solar activity and internal oceanic forcing on the 1,500-year storminess maxima, we re-processed the IRD time series to extract the internal oceanic 1,500-year period, and compared our HSP record with the IRD 1,500-year period time series and the total solar irradiance (TSI) curve ${ }^{18}$ (Fig. 3). One of the main results is a lack of correlation between the HSPs and the filtered TSI curve, as the HSPs alternatively match with low TSI (HSP II and III), transitions between low and high TSI (HSP I and V) or even to an ambiguous signal (HSP IV). We can thus rule out solar forcing as the primary trigger of millennial-scale storminess maxima and associated climate deteriorations in the North Atlantic. Nevertheless, we cannot exclude its possible influence as a weak external driver on coupled ocean-atmosphere dynamics ${ }^{19}$, in particular at shorter (decadal/centennial) timescale ${ }^{20}$. In contrast, the pacing of HSPs with the power spectrum maxima of the 1,500 -year internal oceanic cycle is remarkably strong because 
all HSPs are well correlated with the high phase of the North Atlantic oceanic period.

Recent studies reveal that the dynamics of the subpolar gyre (SPG) circulation is a primary mechanism controlling rapid climatic change in the North Atlantic ${ }^{21}$. Drift-ice input and surface oceanic circulation oscillated between two modes during the late Holocene, with a periodicity of 1,500 years, implying either a strong or a weak SPG (ref. 21). Consistent with the SPG strength mechanism, most of the HSPs seem to coincide with abrupt rises in upper-water-column stratification south of Iceland (Fig. 3e) associated with increases in temperature and salinity (Supplementary Fig. S1). This suggests a westward, reduced extension of the SPG accompanied by a reinforced penetration of warm and saline waters as the subtropical gyre shifts northwards ${ }^{22}$. The good correspondence between the HSPs and temperature increases in the eastern subtropical Atlantic ${ }^{23}$ further supports this hypothesis (Fig. 3f and Supplementary Fig. S1). Hence, all HSPs occur during recognized late Holocene periods of global rapid climate change involving ocean and atmospheric reorganizations ${ }^{2,3}$. In line with contemporary coupled atmospheric-oceanographic observations $^{24}$, we propose that variations in the SPG and subtropical gyre are linked to the strength and location of westerly winds and thus of the storm tracks in the North Atlantic sector. This is also consistent with the mechanisms invoked for the past millennium, as for instance during the cold LIA when weaker and southward-shifted westerlies led to the westward contraction of the SPG (ref. 22). Further corroborating this concept is the good match between the HSPs in northern coastal Europe and periods of increased storminess recorded in a lagoonal coastal system from the northwestern Mediterranean Sea, where these periods of elevated storm activity were associated with a southward displacement of the storm tracks during the cold periods of the Holocene ${ }^{25}$.

Recent studies support our interpretation of a pervasive link between the SPG dynamics and the strength of the westerlies for the past 9,000 years ${ }^{26}$, and climate simulations validate this pattern ${ }^{27}$. The formation of dunefields along northern coastal Europe attributed to enhanced aeolian activity during cool events and the LIA has been further ascribed to large-scale North Atlantic atmospheric changes associated with strong winds that occurred coeval to a southward extension of the polar front ${ }^{11}$. In contrast, the warm Medieval Climate Optimum was characterized by low storm activity ${ }^{13,25}$, with proxy-based and model reconstructions both implying an eastward extension of the SPG and persistent positive North Atlantic Oscillation (NAO) conditions $\mathrm{s}^{22}$. However, the reconciliation of Holocene climateanomaly patterns at millennial scales in the North Atlantic region with the dynamics underlying the NAO at the annualto-decadal timescales remains speculative ${ }^{19}$. Rather, atmosphereocean general circulation model simulations comparing LIA and modern conditions identify reinforced cyclonic activity and an increased north-south thermal gradient south of $50^{\circ} \mathrm{N}$ during the LIA when ice extended southwards in the North Atlantic Basin $^{28}$. Hence, consistent with modern mechanisms, a southward displacement of the westerlies, and associated storm tracks to northern Europe, is implied during late Holocene cool events when the SPG contracted westwards. This would have triggered a rapid reorganization of North Atlantic ocean-atmosphere dynamics, presumably resembling negative NAO conditions ${ }^{22}$, as in 1960 when a southward advance of the polar front triggered the export of sea ice southwards from the Nordic seas during NAO minimum conditions ${ }^{29}$. In light of concerns about the impact of anthropogenic greenhouse gases on extreme storm events in the coming years/decades, our results also indicate that modern coupled ocean-atmosphere dynamics at North Atlantic midlatitudes should trend towards the low phase of the 1,500-year internal oceanic cycle, in contrast to LIA climate conditions. This observation is highly relevant, as it highlights that the recent increase in storm activity ${ }^{30}$ diverges from its natural background variability. This study thus illustrates how coastal sedimentary systems, being directly subjected to changes in storminess, can be used to reconstruct millennial-scale climate variability and climatic forcing factors owing to their high sensitivity to rapid climatic changes. In this sense, they complement marine and terrestrial archives and offer valuable new insights to reconstruct and understand climate change.

\section{Methods}

In both the Seine Estuary and MSMB, seismic reflection surveys were performed using a boomer IKB-Seistec (frequency band of $1-10 \mathrm{kHz}$, shooting rate: $2 \mathrm{~Hz}$, power supply energy: $200 \mathrm{~J}$ ). Data were recorded using the Elics-Delph-Seismic system. Seismic Unix software was used for processing. Vibrocore data were used primarily for sedimentological description and interpretation of sedimentary successions ${ }^{13,14}$. Samples were collected along selected cores for radiocarbon dating (Supplementary Table S1). Absolute dating was corrected by applying a reservoir correction $(R)$ of 400 years with an applied regional deviation $(\Delta R)$ for the English Channel of 56 years. Absolute dating was further calibrated using the calibration programme CALIB 5.0.2. (http://calib.qub.ac.uk/calib/). Calibrated ages indicate values with 2 s.d. $(2 \sigma ; 95 \%$ of confidence). For the past 2,000 years palaeomagnetic data were used to provide a complementary chronological framework on cores collected in the Seine Estuary ${ }^{13}$. The average sedimentation rate calculated on Seine Estuary core $\mathrm{Vk} 31$ is about $0.2 \mathrm{~cm} \mathrm{yr}^{-1}$, which is consistent with the mean rate of sea-level rise since 6,500 cal вр (ref. 13).

The wavelet transform is a band-pass filter, which consists of convoluting the signal with scaled and translated forms of a highly time-localized wavefunction (the filter), the so-called mother wavelet. In this regard, we have used wavelet analyses with a Gaussian filter to reconstruct the millennial-scale component contained in the IRD (ref. 1), density difference ${ }^{21}$ and normalized SST anomaly ${ }^{23}$ time series, by extracting the internal oceanic period of the North Atlantic (about 1,500 years; ref. 4)

Received 3 August 2012; accepted 4 October 2012; published online 11 November 2012

\section{References}

1. Bond, G. et al. Persistent solar influence on North Atlantic climate during the Holocene. Science 294, 2130-2136 (2001).

2. Wanner, H. et al. Mid- to late Holocene climate change: An overview. Quat. Sci. Rev. 27, 19-20 (2008)

3. Wanner, H. et al. Structure and origin of Holocene cold events. Quat. Sci. Rev. 30, 3109-3123 (2011).

4. Debret, M. et al. Evidence from wavelet analysis for a mid-Holocene transition in global climate forcing. Quat. Sci. Rev. 28, 2675-2688 (2009).

5. Lamb, H. H. Climatic variations and changes in the wind and ocean circulation. Quat. Res. 11, 1-20 (1979).

6. Spencer, C. D., Plater, A. J. \& Long, A. J. Rapid coastal change during the midto late Holocene: The record of barrier estuary sedimentation in the Romney March region, southeast England. Holocene 8, 143-163 (1998).

7. Pye, K. \& Neal, A. The Dynamics and Environmental Context of Aeolian Sedimentary Systems Vol 72, 201-217 (Geol. Soc. Sp. Publ., 1993).

8. Gilbertson, D. D., Schwenninger, J-L., Kemp, R. A. \& Rhodes, E. J. Sand drift and soil formation along an exposed North Atlantic coastline: 14,000 years of diverse geomorphological, climatic and human impacts. J. Arch. Sci. 26, 439-469 (1999).

9. Wilson, P., McGourty, J. M. \& Bateman, M. D. Mid- to late-Holocene coastal dune event stratigraphy for the north coast of Northern Ireland. Holocene 14, 406-416 (2004)

10. Jelgersma, S., Stive, M. J. F. \& van der Valk, L. Holocene storm surge signatures in the coastal dunes of the western Netherlands. Mar. Geol. 125, 95-110 (1995).

11. Clemmensen, L. B., Murray, A., Heinemeier, J. \& de Jong, R. The evolution of Holocene coastal dune fields, Jutland, Denmark: A record of climate change over the past 5000 years. Geomorphology 105, 303-313 (2009).

12. De Jong, R., Björck, S., Björkman, L. \& Clemmensen, L. B. Storminess variation during the last 6500 years reconstructed from an ombotrophic peat bog in Halland, southwest Sweden. J. Quat. Sci. 21, 905-919 (2006).

13. Sorrel, P., Tessier, B., Demory, F., Delsinne, N. \& Mouazé, D. Evidence for millennial-scale climatic events in the sedimentary infilling of a macrotidal estuarine system, the Seine estuary (NW France). Quat. Sci. Rev. 28, 499-516 (2009).

14. Billeaud, I., Tessier, B. \& Lesueur, P. Impacts of Late Holocene rapid climate changes as recorded in a macrotidal coastal setting (Mont-Saint-Michel Bay, France). Geology 37, 1031-1034 (2009). 
15. Jackson, M. G. et al. Holocene loess deposition in Iceland: Evidence for millennial-scale atmosphere-ocean coupling in the North Atlantic. Geology 33, 509-512 (2005).

16. O'Brien, S. R. et al. Complexity of Holocene climate as reconstructed from a Greenland ice core. Science 270, 1962-1964 (1995).

17. Oppo, D. W., McManus, J. F. \& Cullen, J. L. Deepwater variability in the Holocene epoch. Nature 422, 277-278 (2003).

18. Steinhilber, F., Beer, J. \& Fröhlich, C. Total solar irradiance during the Holocene. Geophys. Res. Lett. 36, L19704 (2009).

19. Schulz, M., Prange, M. \& Klocker, A. Low-frequency oscillations of the Atlantic Ocean meridional overturning circulation in a coupled climate model. Clim. Past 3, 97-107 (2007)

20. Ineson, S. et al. Solar forcing of winter climate variability in the Northern Hemisphere. Nature Geosci. 4, 753-757 (2011).

21. Thornalley, D. J., Elderfield, H. \& McCave, N. Holocene oscillations in temperature and salinity of the surface subpolar North Atlantic. Nature 457, 711-714 (2009).

22. Copard, $\mathrm{K}$ et al. Late Holocene intermediate water variability in the northeastern Atlantic as recorded by deep-sea corals. Earth Planet. Sci. Lett. 313-314, 34-44 (2012).

23. De Menocal, P. B., Ortiz, J., Guilderson, T. \& Sarnthein, M. Coherent highand low-latitude climate variability during the Holocene warm period. Science 288, 2198-2202 (2000).

24. Curry, R. G. \& McCartney, M. S. Ocean gyre circulation associated with the North Atlantic Oscillation. J. Phys. Oceanogr. 31, 3374-3400 (2001).

25. Sabatier, P. et al. 7000 years of paleostorm activity in the NW Mediterranean Sea in response to Holocene climate events. Quat. Res. 77, 1-11 (2012).

26. Colin, C., Frank, N., Copard, K. \& Douville, E. Neodymium isotopic composition of deep-sea corals from the NE Atlantic: Implications for past hydrological changes during the Holocene. Quat. Sci. Rev. 29, 2509-2517 (2010).

27. Renssen, H. et al. The spatial and temporal complexity of the Holocene thermal maximum. Nature Geosci. 2, 411-414 (2009).
28. Raible, C.C., Yoshimori, M., Stocker, T.F. \& Casty, C. Extreme mid-latitude cyclones and their implications to precipitation and wind speed extremes in simulations of the Maunder Minimum versus present day conditions. Clim. Dynam. 28, 409-423 (2007).

29. Blindheim, J. \& Østerhus, S. The Nordic Seas, main oceanographic features. Geophys. Monogr. 158, 11-37 (2005).

30. Meehl, G. A. et al. in IPCC Climate Change 2007: The Physical Science Basis (eds Solomon, S. et al.) Ch. 10 (Cambridge Univ. Press, 2007).

\section{Acknowledgements}

This work received financial support from the French Seine-Aval 4 programme. P.S. was supported by the CNRS (post-doc at M2C Caen); M.D. was supported by the French Seine-Aval 4 programme (post-doc at M2C Caen). I.B.'s PhD thesis (M2C Caen) was financially supported by the French Ministry of Research. The contribution of J.F.M. to this study was supported in part by the US-NSF and the Comer Science and Educational Foundation. Fieldwork in the MSMB and Seine Estuary was conducted with the RV Côte d'Aquitaine (CNRS/INSU) and the RV Thalia (Ifremer/Genavir), respectively. We warmly thank the M2C-Caen staff for vibrocoring surveys. We are very grateful to P. Gibbard and N. Marriner for constructive comments and cross-reading of the text.

\section{Author contributions}

P.S., M.D. and B.T. designed the study and compiled available data from the literature. P.S. wrote the manuscript. M.D. performed the wavelet analysis. P.S. and M.D. created Figs 1 and 3. I.B. provided all of the data dealing with the MSMB. S.L.J. and J.F.M. contributed to the interpretation of the results. B.T. initiated and guided the project, and provided Fig. 2 . All of the authors discussed the data and provided significant input to the final manuscript.

\section{Additional information}

Supplementary information is available in the online version of the paper. Reprints and permissions information is available online at www.nature.com/reprints. Correspondence and requests for materials should be addressed to P.S. or M.D.

\section{Competing financial interests}

The authors declare no competing financial interests. 